DEMOGRAPHIC RESEARCH

VOLUME 35, ARTICLE 12, PAGES 315-338

PUBLISHED 17 AUGUST 2016

http://www.demographic-research.org/Volumes/Vol35/12/

DOI: 10.4054/DemRes.2016.35.12

Research Article

Trends in the completeness of birth registration in Nigeria: 2002-2010

Olusesan Ayodeji Makinde

Bolanle Olapeju

Osondu Ogbuoji

Stella Babalola

(C) 2016 Olusesan Ayodeji Makinde et al.

This open-access work is published under the terms of the Creative Commons Attribution NonCommercial License 2.0 Germany, which permits use, reproduction \& distribution in any medium for non-commercial purposes, provided the original author(s) and source are given credit.

See http:// creativecommons.org/licenses/by-nc/2.0/de/ 


\section{Contents}

1 Introduction $\quad 316$

2 Methods 319

3 Results 321

4 Discussion 327

5 Limitations 331

$\begin{array}{lll}6 & \text { Conclusions } & 331\end{array}$

$7 \quad$ Acknowledgements 332

$\begin{array}{ll}\text { Contributions } & 332\end{array}$

References 333 


\title{
Trends in the completeness of birth registration in Nigeria: 2002-2010
}

\author{
Olusesan Ayodeji Makinde ${ }^{1,2}$ \\ Bolanle Olapeju ${ }^{3}$ \\ Osondu Ogbuoji ${ }^{4}$ \\ Stella Babalola ${ }^{3}$
}

\begin{abstract}

\section{BACKGROUND}

Nigeria is a signatory to the Convention on the Rights of the Child, which identifies birth registration as a child's right. However, it is unclear how much progress has been made toward attaining universal birth registration in the country.
\end{abstract}

\section{METHODS}

This paper reports findings from a secondary analysis of data from the 2007 and 2011 UNICEF Multiple Indicator Cluster Survey in Nigeria. Trends in birth registration completeness based on year of birth of children and age at survey were computed, tabulated, and graphed.

\section{RESULTS}

Birth registration completeness was $31.5 \%$ and $41.5 \%$ in 2007 and 2011 respectively. Children had better odds of registration across Nigeria in 2011 than in 2007 (OR 1.79, 95\% CI 1.59-2.01), except in the North East geopolitical zone (OR 0.76, 95\% CI 0.551.07). Likewise, older children had better odds of registration than those aged less than one year. Female children had worse chances of registration than their male counterparts (OR 0.92, 95\% CI 0.85-0.99).

\section{CONCLUSION}

Birth registration improved in 2011 over 2007 across Nigeria except in the North East region. However, much still needs to be done to achieve universal birth registration. Birth registration appears to still be influenced by the gender and age of the child.

\footnotetext{
${ }^{1}$ Viable Knowledge Masters, Abuja, Nigeria. E-mail: sesmak@gmail.com.

${ }^{2}$ Demography and Population Studies Program, Schools of Public Health and Social Sciences, University of the Witwatersrand, South Africa.

${ }^{3}$ Bloomberg School of Public Health, Johns Hopkins University, Baltimore, USA.

${ }^{4}$ Harvard School of Public Health, Harvard University, Boston, MA, USA.
} 
Designing and implementing a strategic communication program to educate the population about the processes and benefits of early birth registration may further improve birth registration.

\section{CONTRIBUTION}

This paper provides a rigorous assessment of the progress made toward universal birth registration, which has not been previously demonstrated.

\section{Introduction}

Birth registration is a fundamental right that affords children the opportunity to be documented and establish their nationality. Unfortunately, this right is denied to many children, especially in less developed countries (Pais 2009; UNICEF 1989). Indeed, an estimated 230 million children worldwide have never had their births registered, thereby exposing them to various rights abuses (Bambas 2005; Bequele 2005; Cappa et al. 2014; Corbacho, Brito, and Rivas 2012; Dow 1998; UNICEF 2013). Like other global health challenges, Africa lags behind in the registration of births and is only better than Asia (Bequele 2005; Mikkelsen et al. 2015; UNICEF 2013, 2014a). Less than $10 \%$ of Africa's population live in countries with complete (above $90 \%$ coverage) birth registration (Mahapatra et al. 2007). There is evidence that the rate of birth registration stagnated between 1995 and 2004 (Mahapatra et al. 2007; Setel et al. 2007).

The birth of a child is one of the important events routinely recorded in a Civil Registration System (CRS) (United Nations 2001; World Health Organization 2008). According to the United Nations, civil registration is defined as the "universal, continuous, permanent and compulsory recording of vital events provided through decree or regulation in accordance with the legal requirements in a country" (World Health Organization and World Bank 2014). However, compliance with birth registration is still below 50\% in sub-Saharan Africa and South Asia, 25 years after the Convention on the Rights of the Child (CRC) (Cappa et al. 2014; UNICEF 2014a). The $\mathrm{CRC}$ is an international treaty comprising 54 articles developed in 1989 to recognize the rights of children. It is regarded as "the most widely and rapidly ratified human rights treaty in history" (UNICEF 2014a). The right of children to have their births registered is the seventh article of the CRC.

The importance of CRS data in monitoring health outcomes cannot be understated and requires national and international action to ensure its availability and reliability in monitoring performance of interventions. The post-2015 global health agenda (the Sustainable Development Goals [SDGs]) has made strengthening birth registration one of its major targets (AbouZahr et al. 2015; United Nations 2015; World Health 
Organization and World Bank 2014). In particular, SDG goal 16.9 states as its aim that it will "by 2030, provide legal identity for all, including birth registration" (United Nations 2015). This gives added impetus to measure the performance of the CRS and focus attention on where it is found suboptimal to ensure progress toward meeting the universal birth registration target by the deadline. To this end, the World Health Organization, World Bank, and other partners have developed a ten-year plan, "The Global Civil Registration and Vital Statistics Scaling up Plan (2015-2024)," in the hope of providing the needed guidance to support governments toward the achievement of this goal (World Health Organization and World Bank 2014). Other charities and recognized individuals have also made financial commitments to supporting the improvement of the CRS in developing countries (Lopez and Setel 2015; United Nations Economic and Social Commission for Asia and the Pacific 2014).

Birth statistics are a significant data source in the measurement of health in populations, providing the denominator data for calculating development indicators such as infant mortality and child mortality rates. These are also indicators that are used to measure the quality of health care in a country and the level of access to health care in the population (Alarcón and Robles 2007). Poor data on these parameters can be misleading and drive suboptimal investments in the health system. Additionally, birth statistics are important for monitoring policies and programs on fertility in a country. They can be a significant yardstick for assessing the impact of interventions aimed at controlling population growth and determining the need for an increased intensity of intervention. Furthermore, birth registration is an important source of data for planning for social services such as schools, housing, and security.

Countries with a functioning CRS have been found to have better health outcomes than countries with weaker systems, irrespective of income and other factors that are likely to affect the health status of the population (Phillips et al. 2015). Unregistered children are also vulnerable to trafficking and exploitation by human traffickers (Makinde 2015; Makinde et al. 2015). In addition, unregistered delinquent children can suffer significant legal consequences by receiving heavier than warranted punishments because they are unable to prove their real age (Cappa et al. 2014; Dow 1998). Thus, there is reason to believe that improving birth registration will have several cascading effects on population health and social outcomes in countries. Measuring the performance of birth registration over time can help in determining the rate of progress and the likelihood of meeting national and global targets.

Nigeria is a signatory to the $\mathrm{CRC}$, which establishes the rights of the child. However, the country has struggled to ensure compliance with birth registration, with uncertainties as to the level of progress that has been made. The first formal attempt at institutionalizing civil registration in Nigeria was in 1863, with the promulgation of ordinance 21, with birth registration to start in Lagos. This was eventually expanded to 
cover the entire country by 1917 (Adedini and Odimegwu 2011; National Population Commission, Federal Republic of Nigeria 2008; Salawu 2009). Today the performance of the CRS is still suboptimal. It has been estimated that by 1971 only $7.7 \%$ of births were registered in the old Western Region (Akesode 1980). The Federal Government of Nigeria (FGN) established the National Population Commission (NPC) in 1988 with the responsibility to collect, analyze, and disseminate demographic data in the country. Two of its core roles are to carry out civil registration and to undertake population censuses. The Child Rights Act of 2003 mandated the compulsory registration of every child within 60 days of birth (Isara and Atimati 2015).

Since the NPC was established, there have been conflicting reports on the level of completeness of birth registration in the country. A report on live births, deaths, and stillbirths registration in Nigeria (1994-2007) commissioned by the NPC claims that the birth registration rate was $0.01 \%$ in 1994 and improved to $23.93 \%$ in 2007 (National Population Commission, Federal Republic of Nigeria 2008). Estimates of completeness of birth registration by various authors have focused on specific communities in Nigeria. Their work suggests that the completeness rate is above $65 \%$ in the studied communities, which were consistently above the aggregate rates reported by the NPC (Akande and Sekoni 2005; Tobin, Obi, and Isah 2013; Williams 2014). However, it should be noted that these communities were not representative of the country. Another study evaluated the completeness of a nonconventional active CRS between 1964 and 1974 in Igbo-Ora, a rural town in southwest Nigeria, where completeness was found to be about 95\% (Ayeni and Olayinka 1979). A nationwide survey by the National Bureau of Statistics (NBS) put the birth registration completeness in the country at $30.2 \%$ in 2003 (conflicting with estimates by the NPC of $9.04 \%$ for the same year), which subsequently rose to 42\% in 2011 (Abbas 2014; National Bureau of Statistics 2011). The methodology utilized by the NPC in its analysis was based on data from the national CRS and an estimated number of live births projected from the 1991 census, which was noted to have had some irregularities. With poor compliance regarding birth registration in the country, this may not be the best method for estimating birth registration completeness.

In a bid to improve registration efforts, the NPC set a target for 2010 of $60 \%$ completeness, with the aim of reaching universal registration (100\%) by 2015 (National Population Commission, Federal Republic of Nigeria 2008). To achieve this, the NPC and partners, including UNICEF, put in place various strategies intended to improve birth registration. These included relaxing the fine for late registration and encouraging the registration of all children under 5 years old. For a child to be registered through this program, the parents had to visit a birth registration center or see an itinerant registrar during a community visit. Recently, the establishment of a RapidSMS channel 
(http://br.rapidsmsnigeria.org/) for birth registration reporting by remote registrars was hailed as a good means of improving birth registration monitoring (UNICEF 2012).

Despite canvassing for the improvement of the CRS around the world by the World Health Organization and partners in 2007 (AbouZahr et al. 2007; Hill et al. 2007; Mahapatra et al. 2007; Setel et al. 2007), it remains unclear how much progress has been made in Nigeria, based on conflicting reports. Estimation of completeness is necessary to assess progress toward universal birth registration and to focus interventions on areas with most need. The main alternative to the CRS in Nigeria, the census, is conducted at ten-yearly intervals and can be quite expensive, despite not being able to fulfill the same role as birth registration in providing social protection for children. Additionally, this data source can be politically influenced, besides having several other drawbacks regarding its applicability to birth registration estimation. This was observed in the 1963 Nigerian census, where population figures for the South West were estimated to be about 15\% overenumerated (Ayeni and Olayinka 1979). Nationally representative surveys - such as the Multiple Indicator Cluster Surveys (MICS) and the Demographic and Health Surveys (DHS) - with questions on birth registration may be a better alternative for estimating birth registration completeness in the short term, while the CRS is strengthened (AbouZahr et al. 2012).

This paper presents trends in completeness of birth registration from 2002 to 2010 in Nigeria, and assesses geographic differences in registration completeness using data from the UNICEF MICS rounds 3 and 4. The paper also identified some factors that can predict the birth registration status of a child.

\section{Methods}

Data from the MICS was retrieved from the UNICEF website (www.childinfo.org) following a request and approval process for the use of the data for this study. MICS are nationally representative household surveys conducted in several countries around the world by UNICEF in order to fill in gaps in monitoring the situation of women and children (UNICEF 2014b). In Nigeria the MICS are conducted in collaboration with the NBS. Only two rounds of the MICS have been conducted in Nigeria, MICS 3 and 4, in 2007 and 2011 respectively.

Datasets on children under 5 years as well as on their mothers and households were retrieved. These datasets were linked in order to assess birth registration completeness by sociodemographic characteristics of the mothers and households. In households surveyed in MICS 3 and 4 there were 43,111 children under 5 years old. A total of 1,370 records - mostly from the MICS 3 (1,367 vs. 3 ) - were invalid and omitted from further analysis because information on age, date of birth of the child, or 
the status of birth registration was not recorded. Given that these records represent less than $5 \%(3.2 \%)$ of the available data, we do not expect their exclusion to affect the results significantly. None of the excluded records had information on the ages of the children and most did not have information on maternal age as well. The omitted records were not significantly different from the rest of the data by maternal age or gender of the child. They were, however, significantly different by the location of residence. Records were more likely to be incomplete among children in urban areas. Most of the incomplete records were for children whose mothers were not available for interview. The MICS 4 survey handled these issues possibly by going back to the house or through the exclusion of such children from the study. Thus, this analysis focused on 41,741 valid records. Data analysis was conducted using STATA (version 13) and was weighted appropriately to correct for the multistage sample design of the surveys.

Sampling weights used in our analysis include household weights and individual weights. The household weight for a particular household is the inverse of its household selection probability multiplied by the inverse of the household response rate of its household response rate group. Similarly, the individual weight of a respondent's case is the household weight multiplied by the inverse of the individual response rate. The weights were also stratified by state to reflect differences in selection and to make the data representative of the entire population (Pfeffermann 1996; Rutstein and Rojas 2006).

The dependent variable assessed in this paper is the birth registration status of the children, which was derived using two survey questions from the child questionnaire. The first question asks caregivers if the specific child has a birth certificate. The possible response options to this question are 'Yes, seen,' 'Yes, not seen,' 'No,' and 'Don't know.' If the response is either 'No' or 'Don't know,' the caregiver is asked if the birth has ever been registered with civil authorities. The children for whom the response to the first question is 'Yes, seen' or 'Yes, not seen,' or 'Yes' to the second question, are considered to have been registered. Since the study collected data on children under five years, it was possible to estimate the yearly level of completeness as far back as 2002. The children were categorized by their birth cohort and the proportion that had been registered was then computed for each year. This proportion serves as the level of completeness of the birth registration for that year. A trend analysis was then done using the proportion registered to establish the trend of birth registration completeness over the nine years of review for the entire country and by geopolitical zone. ${ }^{5}$ The state birth registration completeness was also calculated for each state, separately for the MICS 3 and 4.

\footnotetext{
${ }^{5}$ Nigeria has 36 states and the Federal Capital Territory (FCT), grouped into six geopolitical zones: South West (SW), South South (SS), South East (SE), North Central (NC), North West (NW), and North East (NE).
} 
Regression analysis comparing the registration status of children was done between the MICS 3 and 4, controlling for confounders and using the MICS 3 as a reference factor to establish if there had been any statistically significant change in registration status between 2007 and 2011. Adjusted comparisons of the registration status of children were done between the MICS 3 and 4 surveys by the age and gender of the child, geopolitical zone, and state, as well as sector of residence. For the regressions, being registered was coded as ' 1 ,' while being unregistered was ' 0 .'

We further explored the MICS 4 survey for factors that could predict the registration status of a child or affect the chances of registration of the child. We broke down the birth registration status by the age at survey and investigated if the age of the child at survey influenced the registration status of the child. The association of various child (age, gender) and household (mother's age, attendance of ANC during her most recent pregnancy, and current use of a family-planning method, religion of the head of household, wealth quintile, geopolitical zone of residence, and sector of residence, i.e., urban or rural) parameters with birth registration was also investigated. Wealth quintile is a composite indicator created from the ownership of specific household items and the general condition of the home. The relationships were explored using simple and multiple logistic regressions.

\section{Results}

Birth registration completeness rates by birth cohorts between 2002 and 2010 ranged from $30 \%$ to $41 \%$ (Figure 1). The South West zone had the highest rates for all years, maintaining levels above $60 \%$ from 2007 to 2009. The South East zone showed the most progress, as it rose from $38 \%$ to $62 \%$ from 2002 to 2008 . In contrast, the North West zone had the lowest rates overall, increasing by only approximately ten percentage points ( $12 \%$ to $22 \%)$ from 2002 to 2010 . Also noteworthy is the fact that completeness rates in the North East zone have steadily declined since 2005, from 36\% to $20 \%$ in 2010. In fact, all the zones showed a decline in completeness rates in 2009 and four of the six zones declined further in 2010 .

The proportion of children registered at the time of survey was $31.5 \%$ and $41.5 \%$ in 2007 and 2011 respectively. Children surveyed in 2011 had better odds of being registered compared to children surveyed in 2007 (OR 1.79, 95\% CI 1.59-2.01). However, 2011 completeness is still well below the goal (90\%). The increase in registration rates noted in 2011 was seen across children of all ages and gender (Table 1). There was also an improvement in the registration status of children in 2011 across all geopolitical zones except for the North East, which regressed (35\% to 21.9\%). The state level comparison further showed that apart from Gombe and Taraba, which had a 
slight increase in the proportion of children under 5 registered in the North East geopolitical zone in 2011, the other four states within the zone regressed, with Bauchi reducing from $41 \%$ to $6.3 \%$. In all, six states (Adamawa, Bauchi, Borno, Kebbi, Yobe, and Zamfara) had worse birth registration completeness in 2011 than they did in 2007, though this reduction was not always statistically significant (Table 1).

\section{Figure 1: Trends in birth registration completeness by geopolitical zone}

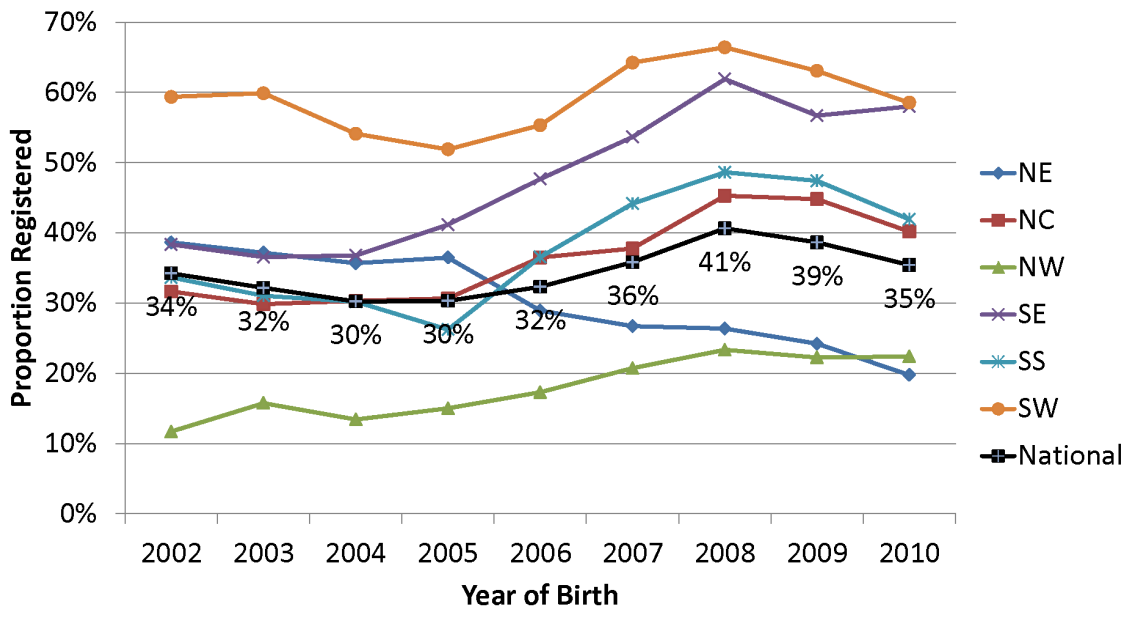

Only six out of 36 states and the Federal Capital Territory had completeness rates above the NPC's 60\% 2010 target for the 2010 birth cohort: Anambra (68\%), Edo (65\%), Ekiti (72\%), Imo (66\%), Lagos (68\%), and Osun (68\%). Zamfara state, however, lagged behind noticeably, with a completeness rate of $9 \%$. Urban-rural variations in registration rates are presented in Figure 2. The data shows that urban registration rates by year of birth were consistently about twice as high as the rural completion rates for all years from 2002 to 2010 . 


\section{Figure 2: $\quad$ Urban-rural trends in birth registration completeness}

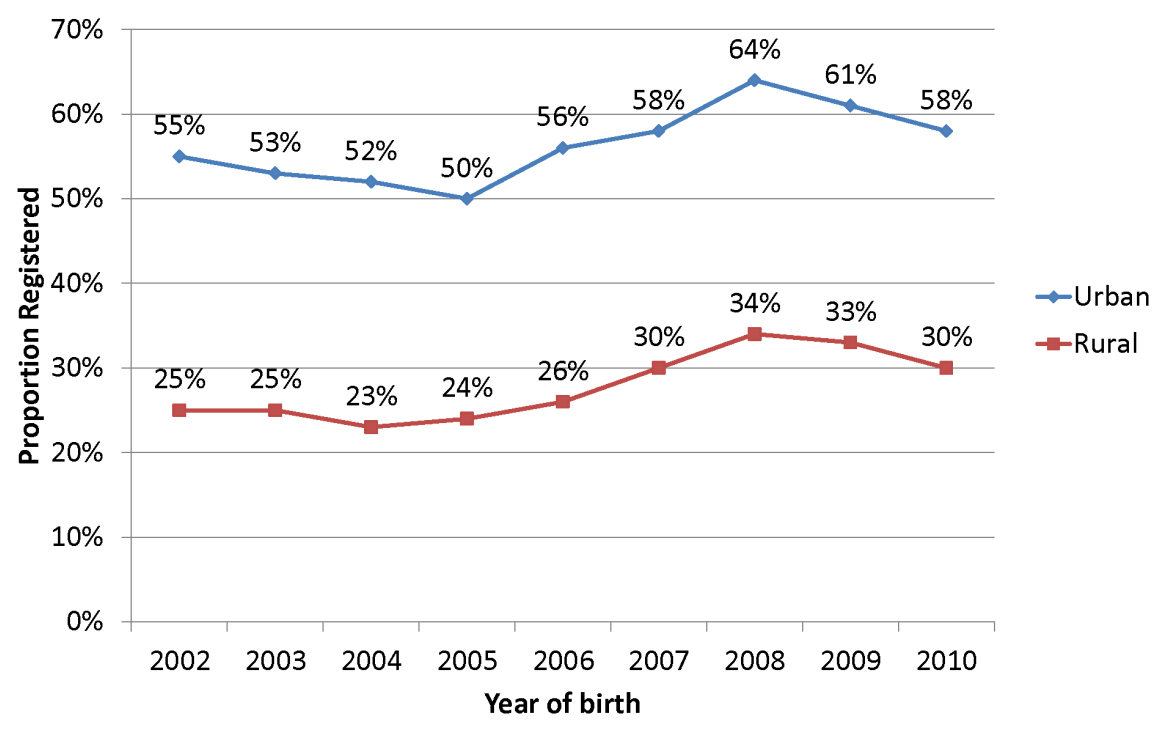

While there is an ongoing insurgency in the northeast of Nigeria, it is unlikely that this crisis alone is responsible for the poor birth registration in the region, as the insurgency was noted to have started in 2009, predominantly in Borno state, before gradually spreading to other states (Adamawa and Yobe) in the region over the following years. Bauchi state, which has seen limited insurgency activity, had the poorest regression of statistics. However, to strike a note of caution, this region might have been more unstable compared to other parts of the country without it being reported. 
Makinde et al.: Trends in the completeness of birth registration in Nigeria: 2002-2010

Table 1: Logistic regression comparing registration status between 2007 and 2011

\begin{tabular}{|c|c|c|c|c|}
\hline $\begin{array}{l}\text { Socio- } \\
\text { demographic } \\
\text { characteristics }\end{array}$ & $\begin{array}{l}2007 \\
\text { (\% registered) }\end{array}$ & $\begin{array}{l}2011 \\
\text { (\% registered) }\end{array}$ & $\begin{array}{l}\text { Unadjusted OR } \\
(95 \% \mathrm{Cl}) \\
(2007=\mathrm{RC})\end{array}$ & $\begin{array}{l}\text { Adjusted OR } 1 \\
(95 \% \mathrm{Cl}) \\
(2007=\mathrm{RC})\end{array}$ \\
\hline Overall & 31.5 & 41.5 & $1.55(1.34,1.78)$ & $1.79(1.59,2.01)$ \\
\hline \multicolumn{5}{|l|}{$\begin{array}{l}\text { Child's age in } \\
\text { years }\end{array}$} \\
\hline 0 & 27.4 & 37.2 & $1.57(1.31,1.90)$ & $1.67(1.40,1.99)$ \\
\hline 1 & 21.7 & 42.8 & $1.61(1.35,1.93)$ & $1.70(1.44,2.02)$ \\
\hline 2 & 30.7 & 44.7 & $1.82(1.52,2.18)$ & $2.18(1.82,2.60)$ \\
\hline 3 & 33.2 & 42.2 & $1.47(1.25,1.73)$ & $1.66(1.41,1.95)$ \\
\hline 4 & 34.7 & 41.4 & $1.32(1.09,1.59)$ & $1.82(1.51,2.20)$ \\
\hline \multicolumn{5}{|l|}{ Child's gender } \\
\hline Male & 32.1 & 42.4 & $1.56(1.34,1.81)$ & $1.75(1.54,1.99)$ \\
\hline Female & 30.8 & 40.6 & $1.54(1.32,1.79)$ & $1.82(1.58,2.09)$ \\
\hline \multicolumn{5}{|c|}{ Geopolitical zones/states $^{2}$} \\
\hline $\begin{array}{l}\text { North Central } \\
\text { (NC) }\end{array}$ & 27.3 & 40.7 & $1.82(1.42,2.34)$ & $1.90(1.53,2.37)$ \\
\hline Abuja FCT & 49.7 & 72.5 & $2.67(1.41,5.06)$ & $2.25(1.21,4.20)$ \\
\hline Benue & 20.7 & 26.1 & $1.35(0.78,2.32)$ & $1.39(0.86,2.26)$ \\
\hline Kogi & 37.5 & 50.1 & $1.67(0.79,3.56)$ & $2.86(1.48,5.56)$ \\
\hline Kwara & 48.4 & 65.2 & $1.99(1.19,3.34)$ & $1.98(1.17,3.34)$ \\
\hline Nasarawa & 21.7 & 35.7 & $2.01(1.09,3.69)$ & $1.88(1.10,3.23)$ \\
\hline Niger & 21.4 & 30.4 & $1.61(0.91,2.85)$ & $2.44(1.42,4.21)$ \\
\hline Plateau & 24.5 & 34.9 & $1.65(0.84,3.23)$ & $1.32(0.74,2.35)$ \\
\hline North East (NE) & 35.0 & 21.9 & $0.52(0.35,0.77)$ & $0.76(0.55,1.07)$ \\
\hline Adamawa & 56.0 & 48.1 & $0.73(0.42,1.27)$ & $0.91(0.59,1.41)$ \\
\hline Bauchi & 41.0 & 6.3 & $0.10(0.03,0.31)$ & $0.31(0.12,0.76)$ \\
\hline Borno & 30.4 & 15.2 & $0.41(0.22,0.78)$ & $0.37(0.20,0.69)$ \\
\hline Gombe & 18.0 & 35.8 & $2.54(0.98,6.59)$ & $2.15(0.89,5.21)$ \\
\hline Taraba & 25.9 & 26.2 & $1.01(0.49,2.10)$ & $1.66(0.75,3.66)$ \\
\hline Yobe & 36.0 & 16.3 & $0.35(0.14,0.88)$ & $0.42(0.21,0.83)$ \\
\hline $\begin{array}{l}\text { North West } \\
\text { (NW) }\end{array}$ & 14.7 & 26.3 & $2.07(1.49,2.87)$ & $3.00(2.31,3.91)$ \\
\hline Jigawa & 10.0 & 19.5 & $2.18(0.97,4.87)$ & $3.99(2.39,6.66)$ \\
\hline Kaduna & 20.0 & 38.5 & $2.50(1.24,5.04)$ & $4.32(2.32,8.07)$ \\
\hline Kano & 13.9 & 28.6 & $2.48(1.23,5.01)$ & $2.29(1.41,3.70)$ \\
\hline Katsina & 18.0 & 34.7 & $2.42(1.24,4.72)$ & $3.03(1.61,5.71)$ \\
\hline Kebbi & 17.0 & 13.4 & $0.75(0.40,1.42)$ & $0.87(0.52,1.46)$ \\
\hline Sokoto & 5.8 & 21.7 & $4.50(1.70,11.89)$ & $8.65(4.33,17.28)$ \\
\hline Zamfara & 10.0 & 9.0 & $0.89(0.43,1.83)$ & $0.68(0.35,1.32)$ \\
\hline
\end{tabular}


Table 1: (Continued)

\begin{tabular}{|c|c|c|c|c|}
\hline $\begin{array}{l}\text { Socio- } \\
\text { demographic } \\
\text { characteristics }\end{array}$ & $\begin{array}{l}2007 \\
\text { (\% registered) }\end{array}$ & $\begin{array}{l}2011 \\
\text { (\% registered) }\end{array}$ & $\begin{array}{l}\text { Unadjusted OR } \\
(95 \% \mathrm{Cl}) \\
(2007=\mathrm{RC})\end{array}$ & $\begin{array}{l}\text { Adjusted OR }{ }^{1} \\
(95 \% \mathrm{CI}) \\
(2007=\mathrm{RC})\end{array}$ \\
\hline \multicolumn{5}{|c|}{ Geopolitical zones/states $^{2}$} \\
\hline South East (SE) & 37.0 & 62.2 & $2.79(2.11,3.70)$ & $3.21(2.52,4.08)$ \\
\hline Abia & 47.6 & 63.0 & $1.87(1.15,3.05)$ & $1.95(1.18,3.23)$ \\
\hline Anambra & 47.6 & 70.1 & $2.59(1.42,4.73)$ & $3.57(2.24,5.71)$ \\
\hline Ebonyi & 20.5 & 44.8 & $3.15(1.50,6.61)$ & $6.96(3.59,13.48)$ \\
\hline Enugu & 34.6 & 52.7 & $2.10(1.07,4.11)$ & $1.89(1.13,3.16)$ \\
\hline Imo & 37.3 & 69.7 & $3.87(2.35,6.37)$ & $6.87(3.31,14.25)$ \\
\hline $\begin{array}{l}\text { South South } \\
\text { (SS) }\end{array}$ & 30.5 & 51.2 & $2.39(1.82,3.15)$ & $2.28(1.74,2.98)$ \\
\hline Akwa-lbom & 17.9 & 52.2 & $5.01(2.74,9.16)$ & $4.32(2.65,7.06)$ \\
\hline Bayelsa & 10.9 & 31.2 & $3.71(2.08,6.62)$ & $5.25(2.84,9.69)$ \\
\hline Cross River & 48.1 & 38.4 & $0.67(0.37,1.22)$ & $0.87(0.53,1.42)$ \\
\hline Delta & 22.8 & 47.1 & $3.02(1.52,5.99)$ & $3.32(1.78,6.20)$ \\
\hline Edo & 46.9 & 72.6 & $3.00(1.53,5.87)$ & $2.63(1.42,4.88)$ \\
\hline Rivers & 30.1 & 56.7 & $3.04(1.76,5.26)$ & $2.82(1.49,5.36)$ \\
\hline $\begin{array}{l}\text { South West } \\
\text { (SW) }\end{array}$ & 51.6 & 64.8 & $1.73(1.33,2.25)$ & $1.81(1.42,2.31)$ \\
\hline Ekiti & 74.2 & 68.4 & $0.75(0.45,1.26)$ & $0.85(0.50,1.44)$ \\
\hline Lagos & 62.0 & 73.0 & $1.66(0.96,2.87)$ & $1.66(0.91,3.02)$ \\
\hline Ogun & 35.3 & 55.2 & $2.26(1.54,3.32)$ & $2.10(1.47,3.00)$ \\
\hline Ondo & 49.2 & 52.3 & $1.13(0.75,1.71)$ & $0.97(0.66,1.42)$ \\
\hline Osun & 47.4 & 77.2 & $3.76(2.32,6.08)$ & $3.21(1.99,5.18)$ \\
\hline Oyo & 41.4 & 57.0 & $1.87(1.11,3.16)$ & $2.38(1.42,4.01)$ \\
\hline
\end{tabular}

Abbreviations: $\mathrm{OR}=$ Odds Ratio; RC = Reference Category

${ }^{1}$ Adjusted for child's age and gender; religion of the head of household, wealth index, sector of residence, and geopolitical zone; maternal age, income, education, number of surviving children, current use of modern family-planning method, and antenatal care usage during pregnancy.

${ }^{2}$ Adjusted state level odds presented were controlled for child's age and gender; household religion, wealth index, and sector of residence; maternal age, income, education, number of surviving children, use of family-planning method, and antenatal care during pregnancy.

Logistic regression revealed predictors of birth registration. Child-level predictors of registration include age and gender, as female children had a lower chance of birth registration than their male counterparts (OR 0.92, 95\% CI 0.85-0.99). Also, children over 1 year old had better odds of being registered than those under one year (Table 2). The location of a child was another significant predictor of birth registration, as urban children had better odds of being registered compared to rural children. However, this observation was not statistically significant after adjustment (Table 2). Furthermore, 
children from other parts of the country had higher odds of birth registration than those in the North East geopolitical zone. These odds were much higher in the south compared to other parts of the north, though not statistically significant for any geopolitical zone (Table 2). It is noteworthy that, after adjustment, the level of significance and pattern of relationship changed significantly. Other predictors of registration include maternal age and education, religion of the mother, household wealth, and mother's engagement in health-seeking behavior. Birth registration odds were highest for children of mothers who were 30-39 years of age, educated to secondary level or above, and from the highest-income households. However, registration was lower in Muslim households and those of other religions compared to Christian households. Birth registration was also noted to be higher among children of mothers who had received antenatal care (ANC) previously at a health facility.

Table 2: Logistic regression showing effect of sociodemographic factors on birth registration status in 2011

\begin{tabular}{lcll}
\hline & \% registered & Unadjusted OR (95\% Cl) & Adjusted OR (95\% Cl) \\
\hline Child's gender & & & \\
Male (RC) & 42.4 & 1.00 & 1.00 \\
Female & 40.6 & $0.93(0.87,1.00)$ & $0.92(0.85,0.99)$ \\
Child's age in years & & & \\
$0(\mathrm{RC})$ & 37.2 & 1.00 & 1.00 \\
1 & 42.8 & $1.26(1.12,1.42)$ & $1.41(1.22,1.63)$ \\
2 & 44.7 & $1.36(1.23,1.50)$ & $1.90(1.66,2.17)$ \\
3 & 42.2 & $1.23(1.09,1.39)$ & $1.74(1.50,2.01)$ \\
4 & 41.4 & $1.18(1.04,1.33)$ & $1.72(1.49,1.99)$ \\
Sector & & & 1.00 \\
Rural (RC) & 32.2 & 1.00 & $1.17(0.98,1.41)$ \\
Urban & 62.9 & $3.57(2.93,4.34)$ & \\
Geopolitical zone of residence & & 1.00 \\
North East (RC) & 21.9 & 1.00 & $1.81(0.63,1.04)$ \\
North Central & 40.7 & $2.45(1.85,3.24)$ & $1.97(0.79,1.20)$ \\
North West & 26.3 & $1.27(0.92,1.75)$ & $1.12(0.90,1.41)$ \\
South East & 62.2 & $5.87(4.38,7.87)$ & $0.73(0.58,0.92)$ \\
South South & 51.2 & $3.75(2.78,5.06)$ & $1.09(0.89,1.33)$ \\
South West & 64.8 & $6.58(4.95,8.74)$ & 1.00 \\
Mother's age & & & $1.41(1.22,1.63)$ \\
$\quad \leq 29$ (RC) & 37.9 & 1.00 & $1.69(1.38,2.06)$ \\
30-39 & 47.2 & $1.47(1.29,1.66)$ & \\
>39 & 37.7 & $0.99(0.85,1.15)$ &
\end{tabular}


Table 2: (Continued)

\begin{tabular}{llll}
\hline & \% registered & Unadjusted OR (95\% Cl) & Adjusted OR (95\% Cl) \\
\hline $\begin{array}{l}\text { Mother's education } \\
\text { level }\end{array}$ & & & \\
None (RC) & 20.5 & 1.00 & 1.00 \\
Primary & 41.6 & $2.76(2.35,3.23)$ & $1.48(1.26,1.75)$ \\
$\begin{array}{l}\text { Secondary or higher } \\
\text { Household religion }\end{array}$ & 66.5 & $7.70(6.55,9.04)$ & $2.48(2.07,2.98)$ \\
Christianity (RC) & 55.3 & 1.00 & 1.00 \\
Islam & 30.4 & $0.35(0.30,0.41)$ & $0.85(0.72,1.02)$ \\
Others & 25.4 & $0.27(0.17,0.43)$ & $0.63(0.42,0.96)$ \\
Household wealth & & & 1.00 \\
Very poor/ Poor (RC) & 17.4 & 1.00 & $2.30(1.94,2.74)$ \\
Medium & 42.6 & $3.53(3.02,4.13)$ & $4.54(3.79,5.42)$ \\
Rich/ Very rich & 69.1 & $10.65(9.15,12.39)$ & 1.00 \\
Mother's marital status & & & \\
Currently in union & 41.6 & 1.00 & $1.00(0.77,1.30)$ \\
(RC) & & & $0.64(0.43,0.96)$ \\
Formerly in union & 43.7 & $1.09(0.85,1.39)$ & 1.00 \\
Never in union & 37.4 & $0.84(0.60,1.18)$ & $1.59(1.39,1.82)$ \\
Mother received ANC & & & 1.00 \\
No (RC) & 32.1 & 1.00 & $1.13(0.97,1.31)$ \\
Yes & 54.3 & $2.52(2.22,2.85)$ & \\
Mother currently uses a family-planning method & 1.00 & \\
No (RC) & 37.6 & $2.51(2.20,2.86)$ & \\
Yes & 60.2 & & \\
\hline
\end{tabular}

Abbreviations: OR = Odds Ratio; RC = Reference Category

${ }^{1}$ Adjusted for child's age and gender; religion of head of household, wealth index, sector of residence, and geopolitical zone; maternal age, income, education, number of surviving children, use of family-planning method, and ANC during pregnancy.

\section{Discussion}

National birth registration completeness by birth cohort was below $50 \%$ consistently throughout the reviewed period. Despite the target of $60 \%$ completeness set by the NPC to be achieved by 2010 (National Population Commission, Federal Republic of Nigeria 2008), this is still some distance away, as the birth registration completeness for the 2010 cohort was just above half the target (35\%). With this state of affairs, the 2015 target of $100 \%$ completeness was very unlikely to be achieved.

We observed that the completeness rate in the South West was above $60 \%$ for the three years preceding 2010. The positive trend in the South East zone is also 
commendable, rising from $38 \%$ in 2002 to $62 \%$ in 2008 . It would be good to explore the kinds of interventions that went into improving the compliance in this zone for others to emulate. The decline in completeness rates experienced across the zones in the 2009 and 2010 cohorts compared to older cohorts is a significant observation which may be the result of a shorter opportunity for registration when compared to the older children. This is also supported by inferential analysis which showed that older children had better chances of being registered than those less than one year old. This finding also makes it clear that birth registration is not usually done immediately after birth in Nigeria. One implication of late registration is that it may be associated with increased errors and falsification of birth dates. It is therefore important to educate parents about the importance of birth registration immediately after birth. It is reasonable to expect that late registration will continue to be prevalent in Nigeria, given that the government has relaxed the birth registration rule in order to enable all children in the country under 5 years old to be legally registered and identified.

With recent evidence suggesting that health outcomes in countries with a functioning CRS are better than in countries without such a system, the need to strengthen the CRS and use the evidence generated for health investment has been stressed (Lopez and Setel 2015; Phillips et al. 2015). This study supports that association, as we note that the North West and the North East geopolitical zones of the country, which have the worst birth registration statistics, have also been observed to have among the worst infant and under-five mortality indices (Adedini et al. 2015; National Population Commission, Federal Republic of Nigeria and ICF International, Maryland USA 2014; Phillips et al. 2015; Wollum et al. 2015). We found that the mother's level of education is positively associated with the child's birth registration status. This relationship may explain in part the poor registration rates observed in the northern part of the country compared to the southern part, as the northern part has lower levels of female education (National Bureau of Statistics 2011; National Population Commission, Federal Republic of Nigeria and ICF International, Maryland USA 2014).

The utilization of modern health care facilities by women is a major predictor for birth registration. This is possibly because those who utilize these services are educated, were provided with information on the benefits of birth registration, and were subsequently linked to the registration centers after delivery. A poor pattern of maternal hospital utilization has been observed to negatively influence the chances of survival of children under five years (Antai 2011). Thus improving hospital utilization for delivery, besides having a direct effect on the health of the women concerned, can contribute toward raising birth registration completeness in Nigeria while also improving outcomes for the children born to these women. However, this is a matter of concern, as only $36 \%$ of deliveries in Nigeria take place in health facilities, according to the 2013 
DHS, a marginal increase from the 2003 estimate of 33\% (National Population Commission, Federal Republic of Nigeria and ICF International, Maryland USA 2014). The persistent poor utilization of health facilities needs to be tackled for this to have an effect on birth registration. In the United States a 1940 evaluation of the CRS found that birth registration was poorer among children who were born out of hospital (Lenhart 1943). Increasing the utilization of health facilities for deliveries was a significant factor in improving the completeness of registration in the United States from $92.5 \%$ to 97.8\% following improvements from about half of deliveries in hospital in 1940 to seven-eighths in 1950 (Shapiro and Schachter 1952). Another study in the Dominican Republic also revealed improved chances of registration with increasing hospital utilization for delivery (Corbacho, Brito, and Rivas 2012). A study conducted in South Africa in 1993 found that involving health workers in birth registration could improve the proportion of births registered from $19 \%$ to $60 \%$ (Nannan et al. 1998). Thus, we infer that there is a need for a fostered relationship between the NPC (which registers births) and the health authorities. While this has been identified and efforts have been made to put in place birth registration points at some public health facilities, there have been very few interventions directed at private health facilities in the country. A recent study in Cross River and Bauchi states found that children of women who were delivered in public health facilities had better chances of birth registration (Adi et al. 2015). While private health facilities make up $33 \%$ of health facilities in Nigeria, they have been noted to serve over half the population (International Finance Corporation 2007; Makinde et al. 2014). Thus, nonintervention at these centers will lead to a huge loss of the target population. In addition, it might be necessary to engage unskilled practitioners, such as traditional birth attendants, who often provide delivery services to women in Nigeria, and encourage them to direct parents to the appropriate government birth registration centers after delivery. Another strategy could be the utilization of community registers at these locations to supplement government registration centers.

The reasons for the poor progress toward achieving universal birth registration in Nigeria are multifaceted. Responsibility for the management of the Nigerian health information system structure cuts across several government institutions, which have their own individual bureaucratic bottlenecks. The NPC is responsible for the registration of births, deaths, and marriages; it has no direct relationship with the Ministry of Health $(\mathrm{MOH})$, which oversees the health facilities where a significant proportion of the births take place. To our knowledge, there is no policy document that details how these institutions should interact. This is a major barrier that has recently caught the attention of policymakers and hopefully will be addressed in due course through legislation. Some countries, such as the Maldives, have tackled this problem by making the $\mathrm{MOH}$ solely responsible for handling the registration of births and deaths (Ye et al. 2012). However, there are drawbacks to this approach, as the MOH usually 
focuses mainly on service statistics and may neglect the CRS, thus undermining it further.

Human resource shortage and budget limitations in the NPC may be alleviated by itinerant registrars, ${ }^{6}$ a system that has been tried and found effective in countries such as Argentina, Ecuador, Mozambique, and Zimbabwe, among others (Dow 1998). Ayeni and Olayinka also described an active CRS that utilized 'family visitors' - a variant of itinerant registrars - to collect routine statistics on births and deaths biweekly in the 1960s and 1970s in Igbo-Ora, Nigeria, which led to completeness rates of over 95\% (Ayeni and Olayinka 1979). As in Igbo-Ora, the utilization of volunteers in a rural community in Kaduna state doubled the level of registration in the community in a three-year period (Idris et al. 2006). Obviously, providing increased opportunity for registration is likely to significantly improve birth registration in Nigeria.

In this study, household wealth was positively associated with birth registration. This finding suggests that conditional cash transfers may help to improve timely registration of birth among the poor in Nigeria. This approach has been shown to improve the adoption of civil registration in India (Baruah et al. 2012). Birth registration should be free whether for regular or late registration (Bequele 2005; Cappa et al. 2014). The NPC obtains a fee for late registration which may further deter indigent parents who, for one reason or another, could not register their child within the mandated 60-day window. This can also lead to falsification of dates of birth if people know they will be charged when their children are being registered late. Though the NPC, as part of its effort to improve birth registration compliance, has relaxed this rule for now, we advocate that the fee for birth registration be completely abolished. Despite being free, there are also concerns that parents are being charged unofficial fees for birth certificates. These fees were identified as deterrents to birth registration by focus group participants in a recent study (Adi et al. 2015).

Many parts of Nigeria operate a patriarchal cultural structure which has characteristically resulted in neglect and poor treatment of female children. In this study, female children had lower odds of birth registration than their male counterparts. Parents should be encouraged to register all their children, irrespective of their sex. Programs may consider additional incentives for parents to register female children.

While the CRS cannot yet provide accurate statistics for birth registration in Nigeria, the surveys which have been advocated as interim measures have presented conflicting results, which further threaten their acceptance. The 2013 birth registration completeness for Nigeria as reported by the NPC in the DHS was noted to have dropped to $31 \%$ against the $42 \%$ reported by the NBS from the MICS survey in 2011 , despite the fact that these two surveys used similar methods to assess birth registration

\footnotetext{
${ }^{6}$ Itinerant registrars visit communities intermittently to register all the vital events that have taken place since their last visit.
} 
completeness. It is thus important to continue to advocate for strengthening of the CRS to provide actual birth statistics figures rather than rely on statistical estimates, which have provided differing results depending on the study. In addition, inclusion of the age at birth registration in future MICS and DHS studies may help improve information on the effect of the age at registration on birth registration status.

\section{Limitations}

Birth registration was assessed using two questions. The second question did not require that the birth certificate be seen by the interviewer. Therefore, we cannot be certain that all those who stated that their child had been registered but did not present a birth certificate had actually registered the child. Parents do receive some form of notification of birth at the health facilities after birth which ought to be taken to the NPC office for an appropriate birth certificate to be issued. Some parents may have assumed that such notification of birth is the birth certificate. Thus, birth registration may have been overreported in this study. The data is also devoid of information on when registration was actually done. This information would have helped in ascertaining the influence the age of a child has on the child's birth registration status. We had to depend on comparing age for age across the two studies and comparing the registration status across different ages among the children to reach our conclusions. The children in urban areas had a higher chance of incomplete records than those in rural areas. This information may suggest that more children from urban centers have been under the care of nonparents, thereby raising issues on the reliability of the information provided.

\section{Conclusions}

Birth registration in Nigeria improved in 2011 over 2007. However, the completeness rate is still a far cry from the target of $100 \%$. Gender continues to have a significant effect on whether the birth of a child is registered. In addition, location influences the chances of registration, as children in the southern part of the country had higher registration chances. Also, urban children had significantly higher registration chances than their rural counterparts. Improving the completeness of civil registration requires a long-term plan, with continuous and sustained implementation of that plan. This must include improving access (especially in rural areas and northern Nigeria) and awareness about birth registration and implementing legislation to remove financial barriers that further deter poor and rural families from registering their children's birth. Improving 
health facility deliveries, better linkages between the NPC and health facilities, and economic empowerment of households should also be used to move toward completeness in birth registration. Birth registration is an important way to protect children from social ills and may entitle them to nationality, health care services, education, and land. This important event and the data it provides cannot be replaced by interim measures to generate birth statistics. Efforts must be directed at ensuring that the target of universal birth registration is met by 2030 .

\section{Acknowledgments}

We acknowledge UNICEF for granting us access to the MICS data for this study.

\section{Contributions}

OAM and SB conceptualized this study and developed the first draft of the manuscript. $\mathrm{OAM}$ and $\mathrm{BO}$ analyzed the data. OAM, BO, OO, and SB edited subsequent versions of the manuscript. All authors agree to the final draft of the manuscript. 


\section{References}

Abbas, A.M. (2014). Effects of distance and population on birth registration coverage: An analysis of gombe state situation, Nigeria. International Journal of Innovative Research and Studies 3(2). http://www.ijirs.com/vol3_issue-2/39.pdf.

AbouZahr, C., Cleland, J., Coullare, F., Macfarlane, S.B., Notzon, F.C., Setel, P., and Szreter, S. (2007). The way forward. The Lancet 370(9601): 1791-1799. doi:10.1016/S0140-6736(07)61310-5.

AbouZahr, C., Rampatige, R., Lopez, A., and deSavigny, D. (2012). When civil registration is inadequate: Interim methods for generating vital statistics. Pacific Health Dialog 18(1): 215.

AbouZahr, C., de Savigny, D., Mikkelsen, L., Setel, P.W., Lozano, R., and Lopez, A.D. (2015). Towards universal civil registration and vital statistics systems: The time is now. The Lancet 386(10001): 1407-18. doi:10.1016/S0140-6736(15)60170-2.

Adedini, S.A., Odimegwu, C., Imasiku, E.N., Ononokpono, D.N., and Ibisomi, L. (2015). Regional variations in infant and child mortality in Nigeria: A multilevel analysis. Journal of Biosocial Science 47(2): 165-187. doi:10.1017/S0021932 013000734 .

Adedini, S.A. and Odimegwu, C.O. (2011). Assessing knowledge, attitude and practice of vital registration system in South-West Nigeria. IFE PsychologIA: An International Journal 19(1): 456-471. doi:10.4314/ifep.v19i1.64613.

Adi, A.E., Abdu, T., Khan, A., Rashid, M.H., Ebri, U.E., Cockcroft, A., and Andersson, N. (2015). Understanding whose births get registered: A cross sectional study in Bauchi and Cross River states, Nigeria. BMC Research Notes 8: 79. doi:10.1186/ s13104-015-1026-y.

Akande, T.M. and Sekoni, O.O. (2005). A survey on birth and death registration in a semi-urban settlement in Middle-Belt Nigeria. European Journal of Scientific Research 8(2).

Akesode, F.A. (1980). Registration of births and deaths in Lagos, Nigeria. Journal of Tropical Pediatrics 26(4): 150-155. doi:10.1093/tropej/26.4.150.

Alarcón, D. and Robles, M. (2007). The challenges of measuring child mortality when birth registration is incomplete. Global Forum on Gender Statistics. http://millenniumindicators.un.org/unsd/Demographic/meetings/wshops/Gender _Statistics_10Dec07_Rome/docs/8.1_Alarcon.pdf. 
Antai, D. (2011). Regional inequalities in under-5 mortality in Nigeria: A populationbased analysis of individual- and community-level determinants. Population Health Metrics 9(1): 6. doi:10.1186/1478-7954-9-6.

Ayeni, O. and Olayinka, A. (1979). An evaluation of a special-type vital statistics registration system in a rural area of Nigeria. International Journal of Epidemiology 8(1): 61-68. doi:10.1093/ije/8.1.61.

Bambas, L. (2005). Integrating equity into health information systems: A human rights approach to health and information. PLoS Med 2(4): e102. doi:10.1371/journal. pmed.0020102.

Baruah, J., Rajkonwar, A., Medhi, S., and Kusre, G. (2012). Effect of conditional cash transfer schemes on registration of the birth of a female child in India. South East Asia Journal of Public Health 3(1): 30-35.

Bequele, A. (2005). Universal birth registration: The challenge in Africa. http://www.riatt-esa.org/sites/default/files/get_file_8f4d1fe7.pdf.

Cappa, C., Gregson, K., Wardlaw, T., and Bissell, S. (2014). Birth registration: A child's passport to protection. The Lancet Global Health 2(2): e67-e68. doi:10.1016/S2214-109X(13)70180-3.

Corbacho, A., Brito, S., and Rivas, R.O. (2012). Birth registration and the impact on educational attainment. Documento de trabajo Nro. IDB-WP-345. Washington, DC: BID. http://www.iadb.org/wmsfiles/products/publications/documents/ 37074928.pdf.

Dow, U. (1998). Birth registration: The 'first'right. UNICEF, The Progress of Nations: $5-11$.

Hill, K., Lopez, A.D., Shibuya, K., and Jha, P. (2007). Interim measures for meeting needs for health sector data: Births, deaths, and causes of death. The Lancet 370(9600): 1726-1735. doi:10.1016/S0140-6736(07)61309-9.

Idris, S.H., Hassan, S.S., Tambaya, A.M., and Sabitu, K. (2006). Documentation of births: A community approach in Tashar - Shari Giwa lga of Kaduna state, Nigeria. Annals of Nigerian Medicine 2(2): 25-28.

International Finance Corporation (2007). The business of health in Africa: Partnering with private sector to improve people's lives. http://mckinseyonsociety.com/thebusiness-of-health-in-africa/. 
Isara, A. and Atimati, A. (2015). Socio-demographic determinants of birth registration among mothers in an urban community in southern Nigeria. Journal of Medicine in the Tropics 17(1): 16. doi:10.4103/2276-7096.148567.

Lenhart, R.F. (1943). Completeness of birth registration in the United States in 1940. American Journal of Public Health and the Nations Health 33(6): 685-690. doi:10.2105/AJPH.33.6.685.

Lopez, A.D. and Setel, P.W. (2015). Better health intelligence: A new era for civil registration and vital statistics? BMC Medicine 13(1): 73. doi:10.1186/s12916015-0333-4.

Mahapatra, P., Shibuya, K., Lopez, A.D., Coullare, F., Notzon, F.C., Rao, C., Szreter, S., and Monitoring Vital Events (2007). Civil registration systems and vital statistics: Successes and missed opportunities. Lancet 370(9599): 1653-1663. doi:10.1016/S0140-6736(07)61308-7.

Makinde, O.A. (2015). Infant trafficking and baby factories: A new tale of child abuse in Nigeria. Child Abuse Review. doi:10.1002/car.2420.

Makinde, O.A., Azeez, A., Bamidele, S., Oyemakinde, A., Oyediran, K.A., Adebayo, W., Fapohunda, B., Abioye, A., and Mullen, S. (2014). Development of a master health facility list in Nigeria. Online Journal of Public Health Informatics 6(2): e184. doi:10.1002/car.2420.

Makinde, O.A., Olaleye, O., Makinde, O.O., Huntley, S.S., and Brown, B. (2015). Baby factories in Nigeria: Starting the discussion toward a national prevention policy. Trauma, Violence \& Abuse: 1-8. doi:10.5210/ojphi.v6i2.5287.

Mikkelsen, L., Phillips, D.E., AbouZahr, C., Setel, P.W., de Savigny, D., Lozano, R., and Lopez, A.D. (2015). A global assessment of civil registration and vital statistics systems: Monitoring data quality and progress. The Lancet 386: 13951406. doi:10.1016/S0140-6736(15)60171-4.

Nannan, N., Bradshaw, D., Mazur, R., and Maphumulo, S. (1998). What is the infant mortality rate in South Africa? The need for improved data. South African Medical Journal = Suid-Afrikaanse Tydskrif Vir Geneeskunde 88(12): 15831587.

National Bureau of Statistics (2011). Nigeria Multiple Indicator Cluster Survey 2011 Report. Abuja, Nigeria: National Bureau of Statistics. http://nigerianstat.gov.ng/pages/download/145. 
National Population Commission, Federal Republic of Nigeria (2008). Report on livebirths, deaths \& stillbirths registration in Nigeria (1994-2007). Abuja, Nigeria: National Population Commission. http://population.gov.ng/images/ Report\%20on\%20Birth-Death-Stillbirth-Registration.pdf.

National Population Commission, Federal Republic of Nigeria and ICF International, Maryland USA (2014). Nigeria Demographic and Health Survey 2013. Abuja/ Rockville: National Population Commission.

Pais, M.S. (2009). Birth registration: Right from the start. UNICEF Innocenti Dig 2: 132.

Pfeffermann, D. (1996). The use of sampling weights for survey data analysis. Statistical Methods in Medical Research 5(3): 239-261. doi:10.1177/096228029 600500303.

Phillips, D.E., AbouZahr, C., Lopez, A.D., Mikkelsen, L., de Savigny, D., Lozano, R., Wilmoth, J., and Setel, P.W. (2015). Are well functioning civil registration and vital statistics systems associated with better health outcomes? The Lancet 386(10001): 1386-94. doi:10.1016/S0140-6736(15)60172-6.

Rutstein, S.O. and Rojas, G. (2006). Guide to DHS statistics. Calverton: ORC Macro. http://citeseerx.ist.psu.edu/viewdoc/download?doi $=10.1 .1 .431 .8235 \&$ rep $=$ rep1\&type $=$ pdf.

Salawu, B. (2009). Strengthening vital registration systems as a source of demographic data for effective socio-economic development planning in Nigeria. Pakistan Journal of Social Sciences 6(4): 200-216.

Setel, P.W., Macfarlane, S.B., Szreter, S., Mikkelsen, L., Jha, P., Stout, S., and AbouZahr, C. (2007). A scandal of invisibility: Making everyone count by counting everyone. The Lancet 370(9598): 1569-1577. doi:10.1016/S0140-6736 (07)61307-5.

Shapiro, S. and Schachter, J. (1952). Birth registration completeness, United States, 1950. Public Health Reports 67(6): 513-524. doi:10.2307/4588130.

Tobin, E.A., Obi, A.I., and Isah, E.C. (2013). Status of birth and death registration and associated factors in the South-south region of Nigeria. Annals of Nigerian Medicine 7(1): 3. doi:10.4103/0331-3131.119979.

UNICEF (1989). Convention on the rights of the Child. [electronic resource] http://digitalcommons.ilr.cornell.edu/cgi/viewcontent.cgi?article=1007\&context $=$ child. 
UNICEF (2012). Nigeria - Using RapidSMS for birth registration | Stories of UNICEF Innovation. [electronic resource] http://www.unicefstories.org/2012/10/17/ nigeria-using-rapidsms-for-birth-registration/.

UNICEF (2013). Every child's birth right: Inequities and trends in birth registration. [electronic resource]. http://www.unicef.org/media/files/Embargoed_11_Dec_ Birth_Registration_report_low_res.pdf.

UNICEF (2014a). 25 Years of the Convention on the Rights of the child: Is the world a better place for children? [electronic resource]. http://www.unicef.org/publi cations/index_76027.html.

UNICEF (2014b). Multiple Indicator Cluster Survey (MICS) [electronic resource]. http://www.unicef.org/statistics/index_24302.html.

United Nations (2001). Principles and recommendations for a vital statistics system. Revision 2. New York: United Nations Publications. http://unstats.un.org/unsd/ publication/SeriesM/SeriesM_19rev2E.pdf.

United Nations (2015). Sustainable development goals [electronic resource]. https://sustainabledevelopment.un.org/topics\#.

United Nations Economic and Social Commission for Asia and the Pacific (2014). Clinton and Bloomberg announce UN partnership to help every woman and girl in Asia-Pacific realize right to legal identity [electronic resource]. http://www.unescap.org/news/clinton-and-bloomberg-announce-un-partnershiphelp-every-woman-and-girl-asia-pacific-realize.

Williams, A.O. (2014). Assessment of the completeness of births and deaths registration in an urban Nigerian community. African Population Studies 27(2): 263-272. doi:10.11564/27-2-473.

Wollum, A., Burstein, R., Fullman, N., Dwyer-Lindgren, L., and Gakidou, E. (2015). Benchmarking health system performance across states in Nigeria: A systematic analysis of levels and trends in key maternal and child health interventions and outcomes, 2000-2013. BMC Medicine 13(1): 208. doi:10.1186/s12916-015-043 $8-9$.

World Health Organization (2008). Framework and standards for country health information systems. http://apps.who.int/iris/handle/10665/43872.

World Health Organization and World Bank (2014). Global civil registration and vital statistics: Scaling up investment plan 2015-2024. The World Bank. 
http://documents.worldbank.org/curated/en/2014/05/19581045/global-civilregistration-vital-statistics-scaling-up-investment-plan-2015-2024.

Ye, Y., Wamukoya, M., Ezeh, A., Emina, J.B.O., and Sankoh, O. (2012). Health and demographic surveillance systems: A step towards full civil registration and vital statistics system in sub-Sahara Africa? BMC Public Health 12(1): 741. doi:10.1186/1471-2458-12-741. 